\title{
Congruence in management control practices
}

\section{Al Bento and Lourdes Ferreira White*}

Merrick School of Business, University of Baltimore,

Baltimore, MD 21201-5779, USA

E-mail: lwhite@ubalt.edu

${ }^{*}$ Corresponding author

\begin{abstract}
We investigate the degree of congruence between preferred and actual levels of ten management control system (MCS) practices in the areas of budgeting, performance evaluation, and compensation. Survey results from responsibility centre managers indicate significant disagreements between preferred and actual levels for most MCS practices. Congruence states of deprivation, satisfaction, and saturation exist for eight MCS practices, and deprivation is the most frequent state for seven MCS practices. Congruence is significantly correlated with performance, and eight MCS congruence variables are markedly related to the congruence variables found to have performance effects.
\end{abstract}

Keywords: congruence; management control; managerial preferences; budgeting; performance evaluation; compensation.

Reference to this paper should be made as follows: Bento, A. and White, L.F. (2006) 'Congruence in management control practices', Int. J. Accounting, Auditing and Performance Evaluation, Vol. 3, No. 3, pp.304-319.

Biographical notes: Al Bento is Professor of Information Systems at the Merrick School of Business, University of Baltimore. He is Editor-in-Chief of the Journal of Information Technology Management and Chair of the Association for Information Systems (AIS) Special Interest Group on Information Systems Security (SIGSEC). A graduate from UCLA, his current research includes projects on information security and performance measurement systems.

Lourdes Ferreira White is Associate Professor of Accounting at the Merrick School of Business, University of Baltimore. A graduate from Harvard, her area of research includes budgeting, performance management, and incentive compensation. She has published in Advances in Management Accounting, Advances in Accounting Education, Journal of Accounting Education, Research in Governmental and Nonprofit Accounting, Human Resource Management Journal, Journal of Corporate Finance, Accounting, Auditing and Accountability Journal, and others. 


\section{Introduction and prior research}

Management Control System (MCS) have undergone major innovations in the last two decades, such as the development of new measures of value creation and the introduction of strategic performance measures. Despite vast organisational resources spent on implementing innovative MCS practices, empirical evidence on their effects is still tentative (Ittner and Larcker, 2003). In this study we examine managerial preferences for MCS practices, to gain a better understanding of how much congruence exists between preferred and actual MCS practices, and the implications of such congruence.

Congruence is defined here as the difference between the preferred level of use of an organisational practice and the actual level of use of that practice. Based on the discrepancy model originally proposed by Alutto and Belasco (1972), when comparing preferred and actual organisational practices, three congruence states may emerge: deprivation (actual use of a practice is less than what is desired), satisfaction (which they called equilibrium, when actual and desired levels match), and saturation (actual use is greater than desired). For example, in this study preferred budget participation may exceed actual participation, evidencing a state of deprivation for this MCS practice; whereas preferred budget tightness may be less than actual budget tightness, evidencing a state of saturation for this MCS practice.

Congruence research has a long tradition in the social sciences, and it has demonstrated that congruence influences many organisational outcomes. Initially focused on the study of congruence between preferred and actual levels of participation in decision making, congruence researchers have argued that participation is not universally desirable, and showed that individuals vary significantly in their desired levels of participation, exhibiting the three congruence states mentioned above (Alutto and Belasco, 1972). The level of congruence between desired and actual participation (rather than actual participation alone) has been found to be a better predictor of satisfaction with decision-making (Driscoll, 1978). Building on Alutto and Belasco's (1972) concept of the three congruence states, other studies in the management information systems literature have shown that congruence between end-users' desired and actual involvement in systems analysis activities has a positive impact on end-user computing satisfaction (Doll and Torkzadeh, 1989, 1991).

The notion of congruence has also been used in a broader sense in organisational research. Researchers have developed the concept of person-organisation fit to include "the congruence between the norms and values of organisations and the values of persons" (Chatman, 1989, p.339). In the human resource management arena, fit has been found to affect the attitudes and behaviours of people in the workplace, influencing job satisfaction, organisational commitment and turnover (O'Reilly et al., 1991), satisfaction with pay (Bento and White, 1998) and even ethics (Sims and Kroeck, 1994). A common theme to those congruence studies is that the degree to which actual organisational practices match individual preferences is more relevant in explaining organisational outcomes than the actual use of the organisational practice alone. If this is true for MCS congruence, then the crucial variable of interest is the difference between preferred and actual MCS practices, rather than actual MCS practices alone.

Even though congruence can be potentially measured for any organisational practice, it has only recently sparked interest among accounting scholars. In the management accounting literature, researchers have studied congruence either from a contingency or a national culture perspective. Merchant (1984), for example, used contingency theory to 
explain congruence between organisational characteristics and budgeting behaviours, and offered evidence that when congruence improves, so does performance. Other studies have used dimensions of national culture to explain congruence between individual values and the design of MCSs (e.g., Chow et al., 1996, 1999).

More recent studies, particularly field-based, have demonstrated the need for MCS to match new managerial practices with the existing organisational culture (Busco et al., 2001). Furthermore, several accounting studies have shown that congruence matters for performance, particularly congruence with respect to budget participation (Clinton and Hunton, 2001) and the use of performance metrics for compensation purposes (Shields and White, 2004). This congruence research in accounting has contributed to our understanding that individuals vary in their preferences for control systems, and that no single MCS practice is universally appropriate for all organisations.

This study contributes to MCS congruence research in three major ways. First, congruence is measured as a continuous variable (preferred minus actual use of MCS practices), allowing us to examine the distribution of congruence states of deprivation, satisfaction and saturation empirically (as recommended by Doll and Torkzadeh (1991)). Second, the relationships between congruence in one MCS practice to congruence in other MCS practices are studied by investigating ten different MCS practices. For example, congruence with respect to the use of financial metrics is related to congruence with respect to the use of non-financial metrics and to congruence with respect to budget emphasis. The ten MCS practices selected for this study represent an overview of the major activities in the MCS process. Third, we test the relationship between congruence in ten MCS practices and managerial performance to assess the practical and theoretical implications of MCS congruence. We conclude that significant disagreements exist between preferred and actual MCS practices, and that congruence in several MCS practices (not just budgeting) may contribute to improved performance.

In the next section we define the ten MCS practices covered in our study. The third section describes our research question and hypotheses, followed by a fourth section on the method for data collection and measurement of the variables. The fifth section comprises the empirical results and the extent to which the hypotheses were supported. The sixth section discusses the results and summarises the conclusions. The seventh section presents their implications for researchers and practitioners.

\section{Management Control System (MCS) practices}

Drawing from the classic MCS framework (reviewed by Anthony and Govindarajan (2004)), we identified ten MCS practices for which we measured congruence, representing each main element of the MCS process: three budgeting practices, four practices related to performance evaluation, and three practices concerning performance-based compensation.

\subsection{Budgeting practices}

Budgeting is one of the most researched MCS activities (Covaleski et al., 2003), as it influences virtually all other MCS practices. Budgets set up standards against which performance is later evaluated, and, in many organisations, the budget is the basis for assigning organisational rewards. We selected three of the most studied budgeting 
practices over which managers would potentially develop strong preferences: participation, emphasis and tightness. Budget participation (sometimes referred to as participative budgeting) relates to the extent to which an individual manager "is involved with, and has influence on, the determination of his or her budget" (Shields and Shields, 1998, p.49). Budget emphasis relates to the extent to which a comparison of budgeted and actual results is emphasised as the basis of performance evaluation and allocation of organisational rewards (Hartmann, 2000). Budget tightness relates to "predetermined budget targets that are perceived to be accurate, important to achieve, and which require serious effort and a high degree of efficiency in accomplishment" (Simons, 1988, p.268). Such targets might include sales goals, cost limitations, or profit objectives.

\subsection{Performance evaluation practices}

The comparison of actual against expected performance levels (usually determined during the budgeting process) is another key MCS activity, as evidenced by the growing literature on performance measurement (Hemmer, 1996; Ittner and Larcker, 1998; Said et al., 2003). We selected four of the most researched practices regarding performance evaluation: the use of financial and non-financial metrics, controllability filters, and Relative Performance Evaluation (RPE). Given the direct impact of these four practices for compensation purposes, we expect them to be potential areas of disagreement between managerial preferences and actual practices. Financial metrics (e.g., costs, revenues or profits) are monetary measures of performance, while non-financial metrics are not expressed in monetary terms (e.g., market share, percent of on-time deliveries).

Two commonly used mechanisms to remove uncertainty from the evaluation process are controllability filters and RPE. Controllability filters relate to the application of the controllability principle, by which a superior makes ex-post adjustments when evaluating performance of a subordinate against a pre-set standard so as to remove uncontrollable factors from the evaluation of the subordinate manager (Merchant, 1987; Shields et al., 1989; El-Shishini, 2001). This area is particularly prone to disagreements between managerial preferences and actual practices, as it closely reflects personal values about uncertainty tolerances held by superiors and subordinates (Bento and White, 1998; Chow et al., 1999).

RPE is another commonly used mechanism to remove uncertainty (Antle and Smith, 1986; Maher, 1987; Gibbons and Murphy, 1990). RPE relates to the comparison of performance of an individual manager against performance data of a peer group (inside or outside the organisation) so as to filter away factors such as industry-related risk or economy-wide factors (e.g., regulatory changes, inflation). By comparing performance of the subordinate against performance of others facing similar constraints, the superior can evaluate the subordinate's effort even in the presence of adverse performance-related events (Bannister and Newman, 2003).

\subsection{Compensation practices}

Based on the outcomes from the performance evaluation activity, rewards are assigned to the individuals deemed to be the high performers. We selected three compensation practices that are susceptible to differences between managerial preferences and actual practices: budget-based compensation, bonuses, and pay potential. Budget-based 
compensation relates to the extent to which monetary rewards are contingent upon performance compared to budget (Waller and Chow, 1985; Merchant, 1989; Chow et al., 1999). Bonuses relate to the extent to which performance-contingent rewards represent a significant portion of total pay (Merchant, 1989; Shields and Young, 1993). Pay potential is a key feature in compensation plan design as it relates to the percentage of base salary that can potentially be paid out as a bonus (Merchant and van der Stede, 2003).

In the next section we formulate the research question and hypotheses regarding congruence between preferred and actual levels for the ten MCS practices discussed above. Due to the limited extant theory on MCS congruence, the hypotheses are presented in general terms, rather than as separate hypotheses for each MCS practice.

\section{Research question and hypotheses}

This study explores the following research question:

To what extent is there congruence between preferred and actual MCS practices, and is MCS congruence related to performance?

We examined this question by formulating the following five hypotheses:

Hypothesis 1: The levels of preferred and actual MCS practices vary significantly, leading to different states of congruence (deprivation, satisfaction and saturation).

In situations where managers prefer a greater use of an MCS practice than what is currently implemented, they experience 'deprivation' with respect to that desired feature of the MCS. Satisfaction is reached when the levels of preferred and actual practices match. Conversely, a state of 'saturation' emerges when managers prefer less use of an MCS practice than what is currently implemented. These three states of congruence are summarised in Table 1.

Table 1 Congruence levels, values and states

\begin{tabular}{lll}
\hline Congruence levels & Congruence values & Congruence states \\
\hline Preferred $>$ actual & Positive & Deprivation \\
Preferred $=$ actual & Zero & Satisfaction \\
Preferred $<$ actual & Negative & Saturation \\
\hline
\end{tabular}

Hypothesis 2: More than one sole state of congruence (deprivation, satisfaction and saturation) exists for each MCS practice.

Different managers develop individual preferences for each MCS practice; thus, the actual level of a particular practice may be less than, match, or exceed the levels preferred by the individuals involved.

Hypothesis 3: A most frequent state of congruence (either deprivation, satisfaction or saturation) exists for each MCS practice.

When the level of actual use of one MCS practice is compared to individual preferences for that practice, there may be a most frequent state of congruence. For some practices, the most frequent state is deprivation (the participant managers' need for that practice is 
not being met); for others, satisfaction may be the most frequent state (the level of actual use of one MCS practice matches managers' preferences for it); still for others, the most frequent state may be saturation (there is inefficient use of that practice beyond the managers' preference for it).

Hypothesis 4: Some specific MCS practice congruence is significantly related to other specific MCS practice congruence.

The design of a coherent MCS requires budgeting, performance evaluation and compensation practices that are consistent with each other. Similarly, managers do not develop preferences for each of those practices in isolation, but are motivated by an overall understanding of what the MCS needs to accomplish. Thus, we expect congruence between preferred and actual levels of a specific MCS practice to be correlated with congruence with respect to some other MCS practices. We test this hypothesis by considering the relationship between congruence in each MCS practice and all other nine MCS congruence practices.

Hypothesis 5: Congruence in some MCS practices is positively related to managerial performance.

When managerial preferences are aligned with actual MCS practices, individual needs are met by the MCS, motivation and satisfaction are expected to increase, and managers can achieve high-quality outcomes, leading to superior performance. On the other hand, when the preference for an MCS practice is not met (deprivation), frustration and dissatisfaction ensue, the quality of the managers' decision making may suffer, leading to decreased effectiveness and lower performance. Similarly, when an MCS practice is used beyond what managers would prefer (saturation), unnecessary resources (e.g., time and energy) are consumed, which may lead to inefficiency and lower performance. As demonstrated by Clinton and Hunton (2001) regarding congruence in budget participation, "deprivation reduces the effectiveness of decision making ... and saturation lowers the efficiency of decision making across the organization" (p.130). We expect that the same will hold true for the MCS practices investigated in this study.

\section{Research method}

\subsection{Data collection}

A survey questionnaire was distributed to 100 managers in the mid-Atlantic area of the USA. The managers were selected to participate in this study based on preliminary interviews to determine if they had direct budget responsibility. Responsibility centre managers were selected because the research question in this study required measurement of managerial preferences for, as well as managerial perceptions of actual use of MCS practices. Participants were assured confidentiality and asked to mail the completed questionnaires in pre-stamped return envelopes with no personal identification. Given that a major aim of this project was to measure the degree of congruence between managers' preferences and their companies' practices in several areas of management control (including sensitive areas such as pay potential and current levels of budget tightness), we made every effort to keep the responses confidential to encourage participation and honesty. Sixty-four managers mailed their completed questionnaires, 
yielding a $64 \%$ response rate. Some participants did not respond to the questions about compensation and performance, causing the number of observations to drop to 56 for those variables (see Table 2). The managers reported an average work experience of five years, managing an average of US\$ 40,000,000 in responsibility centre revenues.

Table 2 Descriptive statistics

\begin{tabular}{|c|c|c|c|}
\hline Variable & Mean & Std. Dev. & $N$ \\
\hline Budget participation - preferred & 24.05 & 3.3 & 62 \\
\hline Budget participation - actual & 20.82 & 5.11 & 62 \\
\hline Budget participation - congruence & 3.23 & 4.22 & 62 \\
\hline Budget emphasis - preferred & 29.44 & 6.64 & 63 \\
\hline Budget emphasis - actual & 26.14 & 7.95 & 64 \\
\hline Budget emphasis - congruence & 3.49 & 7.99 & 63 \\
\hline Budget tightness - preferred & 10.13 & 1.9 & 64 \\
\hline Budget tightness - actual & 11.67 & 1.82 & 64 \\
\hline Budget tightness - congruence & -1.55 & 1.63 & 64 \\
\hline Financial metrics - preferred & 5 & 1.44 & 63 \\
\hline Financial metrics - actual & 3.56 & 1.8 & 64 \\
\hline Financial metrics - congruence & 1.46 & 1.74 & 63 \\
\hline Non-financial metrics - preferred & 3.3 & 2.01 & 63 \\
\hline Non-financial metrics - actual & 2.45 & 1.7 & 64 \\
\hline Non-financial metrics - congruence & 0.83 & 1.44 & 63 \\
\hline Controllability filters - preferred & 20.76 & 4.7 & 62 \\
\hline Controllability filters - actual & 17.33 & 5.12 & 63 \\
\hline Controllability filters - congruence & 3.37 & 3.81 & 62 \\
\hline $\mathrm{RPE}$ - preferred & 3.89 & 1.63 & 63 \\
\hline RPE - actual & 3.8 & 1.85 & 64 \\
\hline $\mathrm{RPE}$ - congruence & 0.13 & 1.74 & 63 \\
\hline Budget-based compensation - preferred & 4.69 & 1.82 & 64 \\
\hline Budget-based compensation - actual & 3.48 & 2.17 & 64 \\
\hline Budget-based compensation - congruence & 1.29 & 1.98 & 62 \\
\hline Bonus - preferred & 31.07 & 22.65 & 57 \\
\hline Bonus - actual & 18.4 & 20.67 & 58 \\
\hline Bonus - congruence & 14.82 & 14.52 & 56 \\
\hline Pay potential - preferred & 75.39 & 177.5 & 59 \\
\hline Pay potential - actual & 31.85 & 32.82 & 61 \\
\hline Pay potential - congruence & 45.42 & 161.4 & 59 \\
\hline Performance & 38.75 & 5.91 & 59 \\
\hline
\end{tabular}

Cronbach alphas for all scales were 0.62 or higher. 


\subsection{Measurement of variables}

The questionnaire included measures validated in previous studies whenever possible. For each MCS practice, the managers rated the extent to which they thought it was actually used in their organisations, and the extent to which they would prefer it to be used, so as to increase performance. Congruence was measured as preferred minus actual levels. Unless otherwise noted, all measurements used a seven-point scale anchored by $1=$ Very Little and $7=$ Very Much.

\subsubsection{Budgeting variables}

The budget participation variable employs Chow et al.'s (1999) four-item instrument adapted from the one developed by Milani (1975), and used in several later studies (e.g., Shields and Young, 1993; Brownell, 1982; Dunk, 1993). The budget emphasis variable employs a six-item instrument adapted from Merchant (1981) and Chow et al. (1993), which was developed based on the original work from Hackman and Porter (1968) and later employed by Dermer (1975). The budget tightness variable consists of a three-item instrument also utilised by Chow et al. (1999), based on Kennis (1979), Simons (1988) and Merchant and Manzoni (1989).

\subsubsection{Performance evaluation variables}

Based on a review of the literature on the choice of performance metrics we selected two metrics, one financial and one non-financial, from the most popular metrics in current practice (Kaplan and Norton, 1996; American Institute of Certified Public Accountants and Maisel, 2001, Shields and White, 2004) that would be available at the responsibility centre level. The two performance metrics selected were efficiency gains (financial) and market share (non-financial), as used in Shields and White (2004). Efficiency gains measure the financial results of a manager's effort to control costs in order to achieve higher profit margins. Market share measures the percentage of a target market that a business unit is able to control. The five items from Chow et al.'s (1999) measure of controllability filters are used to assess the degree to which performance is adjusted for factors beyond the control of the manager, based on Merchant's (1987) original framework. RPE is measured as the extent to which compensation is influenced by the performance of similar units inside or outside the organisation (Maher, 1987).

\subsubsection{Compensation variables}

The budget-based compensation variable is assessed as the extent to which the compensation contract clearly specifies how compensation is related to budget performance (Simons, 1988; Shields and Young, 1993; Chow et al., 1999). The bonus variable is measured by a question used in the same studies cited for budget-based compensation, slightly modified to replace the phrase "extent to which" with the exact percentage of total pay that typically comes from performance-based bonuses, as opposed to pre-set salary. Similarly, the question about pay potential asked for the highest percentage of base salary that the manager could receive as a bonus. 


\subsubsection{Managerial performance variable}

The managerial performance variable is measured by the nine-item instrument originally developed by Mahoney et al. (1963) and widely used in accounting research (e.g., Brownell and Hirst, 1986; Kren, 1992; Nouri et al., 1995; Wentzel, 2002; Chong and Chong, 2002). Each question has a nine-item scale anchored by $1=$ Below Average and $9=$ Above Average.

Table 2 shows descriptive statistics for the 31 variables in this study. The ten congruence variables, computed as preferred minus actual levels, include positive, zero and negative values, depending on whether there is deprivation, satisfaction or saturation with respect to each MCS practice, respectively.

\section{Empirical results}

Table 3 summarises the frequency distributions for the ten congruence variables. For each congruence variable we computed the percentage of respondents that reported a positive, zero, or negative difference between preferred and actual levels of an MCS practice. For example: for budget emphasis, $63.5 \%$ of the respondents report a positive congruence value (they prefer more budget emphasis than actual levels of budget emphasis); $9.5 \%$ of the respondents report a zero congruence value (there is no difference between preferred and actual levels of budget emphasis); and $27 \%$ of the respondents report a negative congruence value (they prefer less budget emphasis than actual levels of budget emphasis). Table 3 is organised so that the congruence variables are listed in increasing order of satisfaction or zero congruence values. The MCS practice with most disagreement (or lowest percentage of respondents reporting perfect congruence between actual and preferred levels) is budget emphasis, with which only $10 \%$ of the respondents were satisfied.

Table 3 Frequency distributions of congruence variables

\begin{tabular}{lccc}
\hline Congruence variable & Positive (\%) & Zero (\%) & Negative (\%) \\
\hline Budget emphasis & 63.5 & 9.5 & 27.0 \\
Bonus & 85.7 & 14.3 & 0.0 \\
Controllability filters & 75.8 & 14.5 & 9.7 \\
Budget tightness & 3.1 & 29.7 & 67.2 \\
Financial metrics & 65.0 & 30.2 & 4.8 \\
Pay potential & 67.8 & 32.2 & 0.0 \\
Budget participation & 62.9 & 33.9 & 3.2 \\
Budget-based compensation & 53.2 & 35.5 & 11.3 \\
RPE & 30.1 & 41.3 & 28.6 \\
Non-financial metrics & 41.2 & 55.6 & 3.2 \\
\hline
\end{tabular}

The frequency distributions for eight of the congruence variables span from positive to negative values, evidencing situations of deprivation, satisfaction and saturation. These results support Hypothesis 1, in that the levels of preferred and actual MCS practices vary among managers, leading to different states of congruence. Only two congruence 
variables, bonuses and pay potential, have no negative values, suggesting that none of the managers considered that their percentage of total pay at risk was too high, or that the percentage of base salary that they can receive as bonuses was excessive. For both of those MCS practices there are no states of saturation, just deprivation or satisfaction. The results in Table 3 also support Hypothesis 2, because more than one sole state of congruence (of either deprivation, satisfaction and saturation) exists for a given MCS practice, and, apart from two exceptions, all three states exist for each MCS practice.

Table 4 further analyses the frequency distributions for the ten congruence variables by showing in italics the most frequent state for each congruence variable. The variables are listed in the order in which they occur in the MCS cycle of budgeting, performance evaluation, and compensation. Deprivation is the most frequent state for seven out of ten MCS practices. In these cases the actual level of the MCS practice is less than the preferred levels for most respondents. Such disagreement between actual and preferred levels is most accentuated for bonuses and controllability filters: more than $75 \%$ of the respondents report that they would prefer a higher use of those practices. The two MCS practices for which the respondents report most satisfaction, or agreement between actual and preferred levels, are the use of RPE and non-financial metrics. Saturation is the most frequent state only for budget tightness, indicating that most managers consider their budgets too tight. Our results strongly support Hypothesis 3, in that there is a most frequent state of congruence (either deprivation, satisfaction or saturation) for all MCS practices.

Table 4 Most frequent state for each congruence variable

\begin{tabular}{lcccc}
\hline Congruence variable & Positive (\%) & Zero (\%) & Negative (\%) & Most frequent state \\
\hline Budget participation & 62.9 & 33.9 & 3.2 & Deprivation \\
Budget emphasis & 63.5 & 9.5 & 27.0 & Deprivation \\
Budget tightness & 3.1 & 29.7 & 67.2 & Saturation \\
Financial metrics & 65.0 & 30.2 & 4.8 & Deprivation \\
Non-financial metrics & 41.2 & 55.6 & 3.2 & Satisfaction \\
Controllability filters & 75.8 & 14.5 & 9.7 & Deprivation \\
RPE & 30.1 & 41.3 & 28.6 & Satisfaction \\
Budget-based compensation & 53.2 & 35.5 & 11.3 & Deprivation \\
Bonus & 85.7 & 14.3 & 0.0 & Deprivation \\
Pay potential & 67.8 & 32.2 & 0.0 & Deprivation \\
\hline
\end{tabular}

The significant correlations among the ten congruence variables are reported in Table 5 and support Hypothesis 4. Each MCS congruence variable is significantly related to at least one other congruence variable, except for budget tightness congruence, which has no statistically significant relationships with any other congruence variable. The two congruence variables correlated with the highest number of other congruence variables are financial metric congruence and bonus congruence. 
Table 5 Correlation coefficients (and $p$-values) of congruence variables

\begin{tabular}{|c|c|c|c|c|c|c|c|c|c|c|c|}
\hline & & 1 & 2 & 3 & 4 & 5 & 6 & 7 & 8 & 9 & 10 \\
\hline 1 & $\begin{array}{l}\text { Budget } \\
\text { participation }\end{array}$ & - & $\begin{array}{c}0.6484 \\
(0.00)\end{array}$ & - & $\begin{array}{c}0.3535 \\
(0.01)\end{array}$ & - & - & - & $\begin{array}{c}0.2287 \\
(0.08)\end{array}$ & - & - \\
\hline 2 & $\begin{array}{l}\text { Budget } \\
\text { emphasis }\end{array}$ & $\begin{array}{c}0.6484 \\
(0.00)\end{array}$ & - & - & $\begin{array}{c}0.4539 \\
(0.00)\end{array}$ & - & - & - & $\begin{array}{c}0.4033 \\
(0.00)\end{array}$ & $\begin{array}{c}0.2149 \\
(0.1)\end{array}$ & - \\
\hline 3 & $\begin{array}{l}\text { Budget } \\
\text { tightness }\end{array}$ & - & - & - & - & - & - & - & - & - & - \\
\hline 4 & $\begin{array}{l}\text { Financial } \\
\text { metrics }\end{array}$ & $\begin{array}{c}0.3535 \\
(0.01)\end{array}$ & $\begin{array}{c}0.4539 \\
(0.00)\end{array}$ & - & - & $\begin{array}{c}0.5787 \\
(0.00)\end{array}$ & $\begin{array}{c}0.3477 \\
(0.01)\end{array}$ & - & $\begin{array}{c}0.3314 \\
(0.01)\end{array}$ & $\begin{array}{c}0.3737 \\
(0.01)\end{array}$ & - \\
\hline 5 & $\begin{array}{l}\text { Non-financial } \\
\text { metrics }\end{array}$ & - & - & - & $\begin{array}{c}0.5787 \\
(0.00)\end{array}$ & - & $\begin{array}{c}0.3180 \\
(0.01)\end{array}$ & - & - & $\begin{array}{c}0.3351 \\
(0.01)\end{array}$ & - \\
\hline 6 & $\begin{array}{l}\text { Controllability } \\
\text { filters }\end{array}$ & - & - & - & $\begin{array}{c}0.3477 \\
(0.01)\end{array}$ & $\begin{array}{c}0.3180 \\
(0.01)\end{array}$ & - & - & - & $\begin{array}{c}0.2334 \\
(0.09)\end{array}$ & - \\
\hline 7 & $\begin{array}{l}\text { Relative } \\
\text { performance } \\
\text { evaluation }\end{array}$ & - & - & - & - & - & - & - & $\begin{array}{c}0.2654 \\
(0.04)\end{array}$ & - & - \\
\hline 8 & $\begin{array}{l}\text { Budget-based } \\
\text { compensation }\end{array}$ & $\begin{array}{c}0.2287 \\
(0.08)\end{array}$ & $\begin{array}{c}0.4033 \\
(0.00)\end{array}$ & - & $\begin{array}{c}0.3314 \\
(0.01)\end{array}$ & - & - & $\begin{array}{c}0.2654 \\
(0.04)\end{array}$ & - & - & - \\
\hline 9 & Bonus & - & $\begin{array}{c}0.2149 \\
(0.1)\end{array}$ & - & $\begin{array}{c}0.3737 \\
(0.01)\end{array}$ & $\begin{array}{c}0.3351 \\
(0.01)\end{array}$ & $\begin{array}{c}0.2334 \\
(0.09)\end{array}$ & - & - & - & $\begin{array}{l}0.3205 \\
(0.02)\end{array}$ \\
\hline 10 & Pay potential & - & - & - & - & - & - & - & - & $\begin{array}{c}0.3205 \\
(0.02)\end{array}$ & - \\
\hline
\end{tabular}

All significant at 0.1 or better.

Congruence between preferred and actual levels of use of financial metrics seems to be a central variable in MCS design because it is related to congruence in $70 \%$ of the MCS practices investigated in this study. Financial metric congruence is significantly and positively related to congruence with respect to six other MCS practices: budget participation, budget emphasis, non-financial metrics, controllability filters, budget-based compensation, and bonuses. Congruence between preferred and actual use of non-financial metrics also seems to be a relevant variable for MCS design, because of its strong relationship with financial metric congruence (0.6). In fact, the second strongest relationship in the correlation matrix is between financial metric congruence and non-financial metric congruence. This result highlights the importance of congruence in both perspectives, validating previous findings that both types of metrics are necessary for a balanced evaluation of performance (Hemmer, 1996; Said et al., 2003; Epstein et al., 2000).

Bonus congruence is significantly related to five other congruence variables: budget emphasis, financial metrics, non-financial metrics, controllability filters and pay potential. This result indicates that agreement about bonuses or the extent to which pay-for-performance accounts for a significant portion of total pay is positively related to congruence about how much emphasis is placed on achieving budget targets and about how performance is evaluated. Furthermore, if managers accept their actual levels of bonuses as a percentage of total pay, they also tend to accept the actual levels of base salary that can potentially be paid out as bonuses. 
In regard to setting targets within the budgeting process, managers who agree about the actual levels of budget participation also agree on average about the degree of budget emphasis, the use of financial metrics, and budget-based compensation. This result shows that agreement about the degree to which managers are allowed to participate in the budgeting process is significantly related to agreements about at least one other MCS practice in each of the critical areas of budgeting, performance evaluation, and compensation. The strongest correlation in the matrix is found for the association between budget participation congruence and budget emphasis congruence.

The results in Table 6 support Hypothesis 5 in that congruence in some MCS practices is positively related to managerial performance. Financial metric congruence, non-financial metric congruence, and bonus congruence are all significantly related to performance. Contrasting these results with the ones in Table 4, we observe that deprivation in the use of financial metrics and bonuses affects performance negatively. In the case of non-financial metrics, even though more than $50 \%$ of the respondents report satisfaction, lack of congruence affects performance negatively. For the other variables (whether or not congruence exists), no significant direct relationship with performance is found. As noted above, congruence about financial and non-financial metrics seem to be critical for MCS design, and the finding that bonus congruence influences performance illustrates arguments from previous studies on the importance of incentive compensation for motivational purposes (Shields and Young, 1993).

Table 6 Correlation coefficients (and $p$-values) of performance and congruence variables

\begin{tabular}{|c|c|c|c|c|}
\hline & Financial metrics & n-financial metrics & Bonus & Performance \\
\hline Financial metrics & - & $0.5787(0.00)$ & $0.3737(0.01)$ & $-0.2549(0.05)$ \\
\hline Non-financial metrics & $0.5787(0.00)$ & - & $0.3351(0.01)$ & $-0.2499(0.05)$ \\
\hline Bonus & $0.3737(0.01)$ & $0.3351(0.01)$ & - & $-0.2431(0.07)$ \\
\hline Performance & $-0.2549(0.05)$ & $-0.2499(0.05)$ & $-0.2431(0.07)$ & - \\
\hline
\end{tabular}

All significant at 0.1 or better.

In summary, the empirical results support all five hypotheses, suggesting that there is considerable variation in the levels of congruence between preferred and actual MCS practices, and that such congruence matters for performance.

\section{Discussion and conclusions}

The purpose of this study was to examine the degree of congruence between preferred and actual levels of MCS practices, and to explore its relationship to performance. Adding to the knowledge gained from studies that examined congruence in one MCS practice such as budget participation (Clinton and Hunton, 2001) or the use of non-financial metrics (Shields and White, 2004), we investigated congruence for ten different MCS practices, based on data collected directly from responsibility centre managers. This afforded us the opportunity to compare degrees of congruence for various practices, and to test for the relationships among them.

The results show that for most MCS practices there is noteworthy disagreement between preferred and actual levels. Deprivation is the most frequent state for seven out 
of the ten MCS practices in this study and, since we also found that congruence is related to performance, it seems to be affecting performance negatively. Satisfaction is the most frequent state for RPE congruence and non-financial metric congruence. Saturation is the most frequent state only for budget tightness. The lowest percentage of satisfaction rate was reported for budget emphasis.

Congruence with respect to the use of financial and non-financial metrics and bonuses is found to be correlated with managerial performance. Furthermore, eight of the ten MCS congruence variables in this study are significantly associated with the three congruence variables found to influence performance. Consistent with other studies (e.g., Bento and White, 2006), positive and significant relationships exist among practices that determine each step of the MCS cycle of:

- $\quad$ setting performance targets

- evaluating performance

- rewarding high performers.

\section{Implications for researchers and practitioners}

Previous studies have documented, using experimental methods, that individuals can accurately assess the degree of budget participation needed to best suit contextual organisational characteristics (Clinton, 1999). Other studies have shown, employing normative models (Vroom and Jago, 1988) that individuals can identify the 'right' levels of participation needed to improve organisational performance (Margerison and Gluse, 1979). In this study, we find empirical evidence, based on responses from responsibility centre managers, that congruence in some MCS practices is related to performance. When managers perceive that their preferences for the use of performance metrics and bonuses are met, their satisfaction and decision-making quality may increase, resulting in improved performance. These results offer additional empirical support to prior congruence research (e.g., Doll and Torkzadeh, 1991; Clinton and Hunton, 2001), and suggest that congruence should not be dismissed as an issue when researching MCS.

A limitation of this study is the use of a non-random sample selected for the purpose of collecting preference and actual data directly from managers with budget responsibility. To encourage a high response rate, the questionnaire length was constrained, so the survey did not inquire about factors that may explain managerial preferences for particular MCS practices. Future research is needed to investigate which demographic, cultural, and other individual factors drive managerial preferences for MCS practices, and to address empirical questions about how preferences vary over time and across individuals in response to actual practices. For example, does congruence tend to increase or decrease over time? And does MCS congruence relate to performance in a nonlinear fashion, as Clinton and Hunton (2001) uncovered for budget participation?

MCS designers and administrators should recognise that congruence between the participants' preferences for MCS practices and their actual implementation is a relevant factor for improved performance. To promote congruence, designers of MCS practices may support participation from all involved managers, even before implementation. The results from this study suggest that achieving consensus only about the three MCS practices that are significantly associated with performance is not enough; attention is 
also needed in the other areas of MCS that are closely related to the three MCS practices found to have performance effects.

\section{References}

Alutto, J. and Belasco, J. (1972) 'A typology for participation in organizational decision making', Administrative Science Quarterly, Vol. 17, pp.117-125.

American Institute of Certified Public Accountants and Maisel, L. (2001) Performance Measurement Practices Survey Results, AICPA, Jersey City, NJ.

Anthony, R. and Govindaranjan, V. (2004) Management Control Systems, McGraw-Hill/Irwin, New York.

Antle, R. and Smith, A. (1986) 'An empirical investigation of the Relative Performance Evaluation of corporate executives', Journal of Accounting Research, Vol. 24, pp.1-39.

Bannister, J. and Newman, H. (2003) 'Analysis of corporate disclosures on Relative Performance Evaluation', Accounting Horizons, Vol. 17, No. 3, pp.235-246.

Bento, A. and White, L. (2006) 'Budgeting, performance evaluation, and compensation: a performance management model', Advances in Management Accounting, Vol. 15, pp.55-83.

Bento, R. and White, L. (1998) 'Participant values and incentive plans', Human Resource Management Journal, Spring, pp.47-59.

Brownell, P. (1982) 'The role of accounting data in performance evaluation, budgetary participation and organizational effectiveness', Journal of Accounting Research, Vol. 20, pp.12-27.

Brownell, P. and Hirst, M. (1986) 'Reliance on accounting information, budgetary participation and task uncertainty: tests of a three-way interaction', Journal of Accounting Research, Vol. 24, No. 2, pp.241-249.

Busco, C., Riccaboni, A. and Scapens, R. (2001) ‘Culture vultures', Financial Management, Vol. 9, pp.30-32.

Chatman, J. (1989) 'Improving interactional organizational research: a model of person-organization fit', Academy of Management Review, Vol. 14, pp.333-349.

Chong, V. and Chong, K. (2002) 'Budget goal commitment and informational effects of budget participation on performance: a structural equation modeling approach', Behavioral Research in Accounting, Vol. 14, pp.65-86.

Chow, C., Kato, Y. and Merchant, K. (1996) 'The use of organizational controls and their effects on data manipulation and management myopia: a Japan vs. US comparison', Accounting, Organizations and Society, Vol. 21, pp.175-192.

Chow, C., Shields, M. and Wu, A. (1993) 'National culture and the transfer of Management Control Systems across national boundaries', Presented at the Accounting, Behavior and Organizations Section conference of the American Accounting Association, January 1994.

Chow, C., Shields, M. and Wu, A. (1999) 'The importance of national culture in the design of and preference for management controls for multi-national operations', Accounting, Organizations and Society, Vol. 24, pp.441-461.

Clinton, B. (1999) 'Antecedents of budgetary participation: the effects of organizational, situational and individual factors', Advances in Management Accounting, Vol. 8, pp.45-70.

Clinton, D. and Hunton, J. (2001) 'Linking participative budgeting congruence to organization performance', Behavioral Research in Accounting, Vol. 13, pp.127-141.

Covaleski, M., Evans, J., Luft, J. and Shields, M. (2003) 'Three theoretical perspectives and criteria for selective integration', Journal of Management Accounting Research, Vol. 15, pp.3-49.

Dermer, J. (1975) 'The interrelationship of intrinsic and extrinsic motivation', Academy of Management Journal, Vol. 18, pp.125-129. 
Doll, W. and Torkzadeh, G. (1989) 'A discrepancy model of end-user computing involvement', Management Science, Vol. 35, pp.1151-1171.

Doll, W. and Torkzadeh, G. (1991) 'A congruence construct of user involvement', Decision Sciences, Vol. 22, pp.443-453.

Driscoll, J. (1978) 'Trust and participation in organizational decision making as predictors of satisfaction', Academy of Management Journal, Vol. 21, pp.44-56.

Dunk, A. (1993) 'The effect of budget emphasis and information asymmetry on the relation between budgetary participation and slack', The Accounting Review, Vol. 68, pp.400-410.

El-Shishini, H. (2001) An Empirical Investigation of the Application of the Controllability Principle and Divisional Performance Measurement in UK Companies, PhD Thesis, University of Huddersfield.

Epstein, M. J., Kumar, P. and Westbrook, R.A. (2000) 'The drivers of customer and corporate profitability: modeling, measuring and managing the causal relationships', Advances in Management Accounting, Vol. 9, pp.43-72.

Gibbons, R. and Murphy, K. (1990) 'Relative Performance Evaluation for chief executive officers', in Enrenberg, R. (Ed.): Do Compensation Policies Matter?, ILR Press, Ithaca, NY.

Hackman, J. and Porter, L. (1968) 'Expectancy theory predictions of work effectiveness', Organizational Behavior and Human Performance, Vol. 3, pp.417-426.

Hartmann, F. (2000) 'The appropriateness of RAPM: toward the further development of theory', Accounting, Organizations and Society, Vol. 25, Nos. 4-5, pp.451-482.

Hemmer, T. (1996) 'On the design and choice of 'modern' management accounting measures', Journal of Management Accounting Research, Vol. 8, pp.87-116.

Ittner, C. and Larcker, D. (1998) 'Innovations in performance measurement: trends and research implications', Journal of Management Accounting Research, Vol. 10, pp.205-238.

Ittner, C. and Larcker, D. (2003) 'Coming up short on nonfinancial performance measurement', Harvard Business Review, Vol. 81, pp.88-95.

Kaplan, R. and Norton, D. (1996) The Balanced Scorecard, Harvard Business School Press, Boston, MA.

Kennis, I. (1979) 'Effects of budgetary goal characteristics on managerial attitudes and performance', The Accounting Review, Vol. 54, pp.707-721.

Kren, L. (1992) 'Budgetary participation and managerial performance: the impact of information and environmental volatility', The Accounting Review, Vol. 67, pp.511-526.

Maher, M. (1987) 'The use of Relative Performance Evaluation in organizations', in Bruns, W. (Ed.): Accounting and Management: Field Study Perspectives, Harvard Business School Press, Boston, MA, pp.295-315.

Mahoney, T., Jerdee, T. and Carroll, S. (1963) Development of Managerial Performance: A Research Approach, South-Western Publishing Company, Cincinnati, OH.

Margerison, C. and Gluse, R. (1979) 'Leadership decision making: an empirical test of the Vroom and Yetton model', The Journal of Management Studies, Vol. 16, pp.45-55.

Merchant, K. (1981) 'The design of the corporate budgeting system: Influences on managerial behavior and performance', The Accounting Review, Vol. 56, pp.813-829.

Merchant, K. (1984) 'Influences on departmental budgeting: an empirical examination of a contingency model', Accounting, Organizations and Society, Vol. 9, pp.291-307.

Merchant, K. (1987) 'How and why firms disregard the controllability principle', in Bruns, W. (Ed.): Accounting and Management: Field Study Perspectives, Harvard Business School Press, Boston, MA, pp.316-338.

Merchant, K. (1989) Rewarding Results: Motivating Profit Center Managers, Harvard Business School Press, Boston, MA.

Merchant, K. and Manzoni, J. (1989) 'The achievability of budget targets in profit centers: a field study', The Accounting Review, Vol. 64, pp.539-558. 
Merchant, K. and van der Stede, W. (2003) Management Control Systems, Pearson Education, Prentice-Hall, Financial Times, Harlow, England.

Milani, K. (1975) 'Budget-setting, performance and attitudes', The Accounting Review, Vol. 50, pp.274-284.

Nouri, H., Blau, G. and Shahid, A. (1995) 'The effect of Socially Desirable Responding (SDR) on the relation between budgetary participation and self-reported job performance', Advances in Management Accounting, Vol. 4, pp.163-177.

O'Reilly, C., Chatman, J. and Caldwell, D. (1991) 'People and organizational culture: a profile comparison approach to assessing person-organization fit', Academy of Management Journal, Vol. 34, No. 3, pp.487-516.

Said, A., HassabElnaby, H. and Wier, B. (2003) 'An empirical investigation of the performance consequences of non-financial measures', Journal of Management Accounting Research, Vol. 15, pp.193-224.

Shields, J. and Shields, M. (1998) 'Antecedents of participative budgeting', Accounting, Organizations and Society, Vol. 23, pp.49-76.

Shields, J. and White, L. (2004) 'The measurement gap in paying for performance: actual and preferred measures', Advances in Management Accounting, Vol. 12, pp.59-84.

Shields, M. and Young, S.M. (1993) 'Antecedents and consequences of participative budgeting: evidence on the effects of asymmetrical information', Journal of Management Accounting Research, Vol. 5, pp.265-280.

Shields, M., Chow, C. and Whittington, R. (1989) 'The effects of state risk and controllability filters on compensation contract and effort choice', Abacus, Vol. 25, pp.39-55.

Simons, R. (1988) 'Analysis of the organizational characteristics related to tight budget goals', Contemporary Accounting Research, Vol. 5, No. 1, pp.267-283.

Sims, R. and Kroeck, K. (1994) 'The influence of ethical fit on employee satisfaction, commitment and turnover', Journal of Business Ethics, Vol. 13, pp.939-947.

Vroom, V. and Jago, A. (1988) The New Leadership: Managing Participation in Organizations, Prentice-Hall, Englewood Cliffs, NJ.

Waller, W. and Chow, C. (1985) 'The self-selection and effort effects of standard-based employment contracts: a framework and some empirical evidence', The Accounting Review, Vol. 60, pp.458-476.

Wentzel, K. (2002) 'The influence of fairness perceptions and goal commitment on managers' performance in a budget setting', Behavioral Research in Accounting, Vol. 14, pp.247-271. 